\title{
Palabras extrañas a sí mismas: una aproximación desde la hermenéutica intercultural al bilingüismo de Julia Kristeva*
} The Eloquence of Polyglots: Julia Kristeva's
Bilingualism and Intercultural Hermeneutics

TOMÁs ESPINO

Lingüística general y Teoría de la literatura

Facultad de Filosofía y Letras

Universidad de Granada

Campus universitario de Cartuja

C/ Profesor Clavera s/n. Granada, 18071

tespino@correo.ugr.es

Orcid ID 0000-0001-8030-4415

Resumen: El abandono de la lengua materna y la adquisición del francés como lengua de escritura desempeñan un papel fundamental a lo largo de toda la obra teórica y literaria de Julia Kristeva. El presente trabajo se propone estudiar las posiciones de Kristeva respecto al cambio de lengua, ubicándolas en su contexto histórico e ideológico y analizándolas a la luz de las numerosas aportaciones teóricas dedicadas al multilingüismo literario surgidas en los últimos años, prestando especial atención a su concepción de la lengua y del individuo como extraños a sí mismos. El presente trabajo trata además de poner en relación las ideas de Kristeva con las teorías de la hermenéutica intercultural, que entiende la lectura de textos literarios extranjeros como una manera de sacar a la luz los prejuicios de la cultura propia para poder acercarse al mundo del texto respetando su alteridad irreductible.

Palabras clave: Julia Kristeva. Multilingüismo literario. Hermenéutica intercultural. El otro. Lengua materna.
RECIBIDO: 19 DE SEPTIEMBRE DE 2017 ACEPTADO: 18 DE DICIEMBRE DE 2017

\begin{abstract}
The loss of the mother tongue and the acquisition of French as the language of her writing play a capital role in the theoretical and literary work of Julia Kristeva. This paper aims to analyze Kristeva's ideas on bilingualism and language loss as well as their historical and ideological context by using the latest scholarship on literary multilingualism. Special attention will be paid to Kristeva's concept of language and the individual as strangers to themselves. Additionally, this paper endeavors to establish a channel of communication between Kristeva's ideas and the theories of intercultural hermeneutics, a school which proposes reading foreign literary texts as a means of unearthing the prejudices of our own culture while approaching the world of the text respecting its irreducible otherness.
\end{abstract}

Keywords: Julia Kristeva. Literary Multilingualism. Intercultural Hermeneutics. The Other. Mother Tongue.

\footnotetext{
* Este trabajo se ha realizado en el marco del proyecto de investigación "Actualidad de la hermenéutica" (FFI2013-41662-P), financiado por el Ministerio de Economía y Competitividad para el periodo 2014-2018.
} 
E 1 contacto con el extranjero y con su idioma, constante en todas las épocas y culturas a través de migraciones, viajes o textos procedentes de otras regiones del globo, no ha hecho sino intensificarse en las últimas décadas, caracterizadas por la aceleración de los procesos de globalización a todos los niveles. La apertura del canon hacia textos procedentes de otras culturas, especialmente desde el giro hacia la literatura mundial en la literatura comparada, así como la multiplicación de las prácticas multilingües y la institucionalización de su estudio, hacen necesario un replanteamiento de las bases teóricas de la producción e interpretación de este tipo de obras. ¿Cómo llega un escritor a cambiar de lengua, a hacerse extranjero para sí mismo? ¿Cómo interpretar estos textos o, en general, los textos procedentes de otras tradiciones culturales?

La primera parte de este trabajo tratará de ofrecer un acercamiento a las posiciones de Julia Kristeva con respecto al bilingüismo y a la pérdida de la lengua materna, expresadas sobre todo en Étrangers à nous-mêmes (1988) y que aparecen con fuerza no solo en el resto de su obra teórica, sino también en su menos conocida faceta novelística. Los estudios dedicados al bilingüismo de Julia Kristeva publicados hasta la fecha (ver Calero/Pujante/Teruel; Fort; IvantchevaMerjanska), pese a su exhaustiva lectura de las obras de la autora búlgara, no hacen apenas uso de la bibliografía teórica dedicada al multilingüismo literario. El presente trabajo se propone presentar brevemente la posición de Julia Kristeva con respecto al cambio de lengua, ubicándola en su contexto histórico e ideológico y analizándola a la luz de las numerosas aportaciones teóricas dedicadas al multilingüismo literario que han surgido en el campo de la literatura comparada en los últimos años. Nuestra segunda parte tendrá como objetivo abordar una idea aneja, asimismo desarrollada en Étrangers à nous-mêmes: el concepto de extranjero interior o desconocido para sí mismo. Este concepto, que en el caso de Kristeva posee una evidente raigambre psicoanalítica, se presta a entrar en diálogo con la llamada "hermenéutica intercultural", surgida en un contexto temporal próximo pero de características muy diferentes: el ámbito de la didáctica de la lengua y la literatura alemanas para extranjeros en la primera parte de la década de los 80. La exploración de esta relación -que no sería en ningún caso de tipo genético, puesto que no consta que Kristeva fuera lectora de este tipo de obras- podría suscitar interés por la hermenéutica intercultural más allá de su disciplina y país de origen al sugerir sus posibles aplicaciones actuales en filosofía, teoría de la literatura o literatura comparada.

La literatura escrita en un idioma distinto de la lengua materna es prácticamente tan antigua como la literatura misma. Desde los albores de la escri- 
tura, un gran número de autores se decantó por utilizar una segunda o tercera lengua en algunas de sus obras o incluso en el conjunto de su producción. Desde Luciano de Samósata hasta Jorge Semprún, pasando por John Milton, Francisco de Quevedo o los casos más conocidos de Joseph Conrad, Samuel Beckett y Vladimir Nabokov, un amplio y heterogéneo conjunto de autores decidió adoptar una nueva lengua, bien por razones más o menos prácticas, como la búsqueda de un público más amplio o el deseo de situarse dentro de la tradición literaria de una lengua de prestigio, o por razones ideológicas como la voluntad de abandonar la lengua propia de un régimen represivo para escribir en lenguas asociadas a valores más democráticos. Otros escritores, especialmente en la Edad Media y en el Renacimiento, escribieron en una lengua o en otra en función del género o de la temática de sus composiciones. La diversidad de razones por las cuales un escritor decide escribir en un segundo idioma da fe de la amplitud y complejidad de este fenómeno. ${ }^{1}$

En un sentido amplio, el multilingüismo literario (también conocido como translingüismo, exofonía o heteroglosia) ${ }^{2}$ podría definirse como "el fenómeno de los escritores que escriben en más de un idioma o al menos en un idioma distinto de su primera lengua" (Kellman, IX). ${ }^{3}$ El bilingüismo literario no se limita a las obras escritas íntegramente en una lengua distinta de la lengua materna del autor. Otras prácticas, tales como la combinación de varios idiomas en un mismo texto o code-switching, definida por Kremnitz como "multilingüismo intratextual" (19) o el denominado "bilingüismo latente", es decir, la situación propia del escritor ubicado en un contexto lingüístico distinto al de su país de origen que, aunque sigue escribiendo en su lengua materna, recibe la influencia de la lengua extranjera que le rodea en su vida cotidiana (Guillén 124), pueden también considerarse como genuinamente multilingües.

Pese a la antigüedad y relativa frecuencia del fenómeno del multilingüismo literario, no fue hasta los años 60 y 70 del siglo pasado cuando surgieron los primeros estudios dedicados explícitamente al tema, sobre todo a partir de trabajos dedicados a la obra bilingüe de Beckett. Sin embargo, resulta preciso señalar que ciertos filósofos ya se habían manifestado anteriormente sobre la escritura en una segunda lengua y la posibilidad de la pérdida de la lengua ma-

1. Para una discusión pormenorizada acerca de los motivos de la elección de una lengua u otra en la literatura, ver Kremnitz.

2. Para una discusión terminológica ver Stockhammer/Arndt/Naguschewski.

3. Todas las traducciones de este trabajo son nuestras. 
terna, cuestión que les atañía muy de cerca puesto que algunos de ellos, como el caso de Theodor W. Adorno y Hannah Arendt, se habían visto forzados a exiliarse en un país de distinto idioma. En el caso de Adorno, las reflexiones en torno al multilingüismo se centran sobre todo en su defensa del uso de Fremdwörter o palabras de origen extranjero, mientras que Arendt manifestó en una entrevista televisiva con Günter Gaus que, pese a haber escrito gran parte de su obra en inglés, la lengua materna era prácticamente lo único que había conservado intacto de su vida en Alemania después de refugiarse en Estados Unidos.

En el ámbito de los estudios literarios, el primer trabajo que ofreció una visión panorámica del fenómeno del multilingüismo literario fue The Poet's Tongues, de Leonard Foster, un recorrido histórico por las figuras más relevantes del multilingüismo en la poesía que reivindicaba la importancia de este tipo de obras, a menudo caídas en el olvido en los estrechos márgenes de los cánones literarios nacionales monolingües. Sin embargo, no será hasta la siguiente década cuando el interés por el multilingüismo literario alcance un peso específico dentro del panorama de los estudios literarios, con la publicación en 1989 de Alien Tongues: Bilingual Russian Writers of the 'First' Emigration (Klosty), un revolucionario estudio de las trayectorias lingüísticas de diversos escritores rusos exiliados complementado con los aportes de la entonces todavía naciente neurolingüística. Los años 70 y 80 coinciden además con la consolidación del vínculo de los estudios traductológicos con la teoría literaria y la literatura comparada con la publicación de obras como After Babel (1975), de George Steiner -quien había dedicado previamente un ensayo al multilingüismo literario en Extraterritorial (1972)- o L'Épreuve de l'étranger, de Antoine Berman (1984). Asimismo, estos años se caracterizan por una renovación del interés por la construcción de imágenes y estereotipos nacionales en el área de la imagología gracias a los aportes de Hugo Dyserinck y Daniel-Henri Pageaux, así como con la aparición de obras acerca de la diversidad humana y la percepción del extranjero, como Nous et les autres, de Tzvetan Todorov. En Alemania, este proceso se ve reflejado en el desarrollo de la germanística y la hermenéutica interculturales y en la institucionalización de la literatura escrita por inmigrantes con la creación del Premio Adalbert von Chamisso (1985), otorgado hasta 2017 a autores que escriben en alemán sin ser esta su lengua materna. Es en este contexto de fascinación por el multilingüismo y la imagen del otro, determinado en gran parte por la intensificación de flujos migratorios de todo tipo (inmigración económica, exilios políticos, refugiados de conflictos bélicos), donde aparece en 1988 Étrangers à nous-mêmes. 
Julia Kristeva, que había aprendido francés gracias a una educación "francófila y francófona" en una escuela francesa regentada por monjas dominicas en su Bulgaria natal (Kristeva 1983, 39), llegó por primera vez a Francia en 1965 para continuar sus estudios. Durante sus primeros años en el país galo, su contacto con el francés se hace cada vez más intenso, pero es sobre todo la experiencia de ser psicoanalizada en francés en los años 70, tal y como explicó la propia Kristeva en una entrevista televisiva con Bernard Pivot, la que culmina su transformación lingüística: su segunda lengua se convierte en la lengua en que expresar su infancia y en una especie de segunda lengua materna. Desde entonces, su fulgurante carrera académica e intelectual se desarrolla íntegramente en lengua francesa, sin que ello signifique en ningún caso una asimilación total a la cultura francesa. Más bien, tal y como señaló Roland Barthes en su reseña del primer libro de Kristeva, Semeiotikê: Recherches pour une sémanalyse (1969), es precisamente su posición de extranjera la que le permite cuestionar los prejuicios de las convenciones lingüísticas, académicas y culturales francesas (Barthes 477). Asimismo, el nacimiento de David, el hijo discapacitado con el que Kristeva habla exclusivamente en francés, constituye otro punto de anclaje a la lengua francesa como expresión de valores maternales (Ivantcheva-Merjanska 117).

Como hemos indicado, Étrangers à nous-mêmes aparece en 1988, cuando Julia Kristeva llevaba por tanto ya más de dos décadas en Francia y escribiendo en francés. La obra comienza con unas reflexiones generales, a menudo de carácter marcadamente autobiográfico en torno a la figura del extranjero ("Toccata et fugue pour l'étranger"), para pasar en su segunda parte a una profunda genealogía del concepto de extranjero. El propio título de la primera parte del libro indica su orientación: Kristeva trata de "tocar" o rozar al extranjero manteniendo su especificidad, es decir, sin intentar asimilarlo o anularlo. La reflexión en torno al bilingüismo y a la pérdida de la lengua materna se concentra en las secciones "Le silence des polyglottes" y "Explosion: sexe ou maladie", aunque permean el resto de "Toccata et fugue pour l'étranger". Desde el primer momento, la pérdida de la lengua materna se asocia a una ruptura con la infancia y con la corporalidad más profunda: "Ne pas parler sa langue maternelle. Habiter des sonorités, des logiques coupées de la mémoire nocturne du corps, du sommeil aigre-doux de l'enfance" (26-27). El tono personal alcanza su máxima expresión en la siguiente frase, que pasa a la segunda persona y hace referencia a la experiencia de Julia Kristeva como madre de un hijo discapacitado: "Porter en soi comme un caveau secret, ou com- 
me un enfant handicapé -chéri et inutile-, ce langage qui se fane sans jamais vous quitter" (27). La metáfora de una cripta secreta que funciona como receptáculo del primer idioma en el interior de cada extranjero -que reaparecerá años más tarde en "Bulgarie ma souffrance" (42) y en Au Risque de la pensé (101) - va acompañada de la inversión de la lengua materna en una "lengua hija" -cada vez más vulnerable pero siempre amada-, manteniendo de este modo el vocabulario orgánico y cargado de afectividad que caracteriza todo el discurso kristeviano en torno a la lengua. Años más tarde, Kristeva volvería a utilizar esta metáfora de la lengua materna como una enferma o como un cuerpo cadaverizado: "Le bulgare est déjà pour moi une langue presque morte. [...] L'exil a cadavérisé ce vieux corps, pour lui en substituer un autre -d'abord fragile et artificiel-, ensuite de plus en plus indispensable, et maintenant le seul vivant, le français" $(1995,42)$.

La imagen de la lengua materna como un órgano mutilado, enfermo o insensible se repite en multitud de escritores multilingües. Eva Hoffman habla de cómo su polaco materno se atrofia y se encoge a los pocos meses de llegar a Canadá (107), mientras que la canadiense Nancy Huston describe cómo su inglés se asemeja a un órgano atrofiado y dormido en Francia (Huston/ Sebar 74). Por su parte, Vladimir Nabokov equipara el proceso de escritura en una segunda lengua con el doloroso aprendizaje de los movimientos cotidianos tras perder varios dedos en una explosión (47). En otros casos, es el propio bilingüismo el que se convierte en una "enfermedad" para Elsa Triolet (54) o en una "infección" para Jacques Hanoun (Bennani 33). En algunos casos, como el de Agota Kristof, la nueva lengua amenaza con acabar matando a la lengua materna (20).

El lado "asesino" del bilingüismo aparece de manera explícita y recurrente en toda la obra de Kristeva, sobre todo bajo la metáfora de la muerte de la madre. En "Bulgarie, ma souffrance", Kristeva equipara el abandono de la lengua materna con el "matricidio" $(1995,42)$, mientras que en su novela Meurtre à Byzance (2004), última parte de la trilogía iniciada con Le Vieil Homme et les loups (1991), el cambio de lengua de Beckett vuelve a designarse con el mismo término de "matricidio" (118). En Possessions (1996), segunda novela de la misma trilogía, la logopeda Pauline, tras experimentar un proceso de cambio de lengua como terapia para superar la traumática muerte de su hermano, decapita a Gloria, traductora y madre de Jerry, un niño sordo que presenta graves problemas de adquisición del lenguaje. Pauline acaba sustituyendo a Gloria como madre de Jerry y asumiendo su formación lingüística. 
Ivantcheva-Merjanska interpreta este episodio en términos psicoanalíticokristevianos como el necesario matricidio de la madre biológica que constituye el paso previo para el desarrollo lingüístico e intelectual mediante una madre sustitutiva (172). En efecto, el concepto de matricidio permea toda la obra de Kristeva como la condición sine qua non que permite el desarrollo del individuo $(1989,38)$, como el requisito del pensamiento $(2000,213)$, o como la condición para acceder al símbolo (2000, 219). Ya en Étrangers à nous-mêmes, Kristeva erigía el asesinato simbólico de los padres, común a todo extranjero, como una alucinación placentera y liberadora (35).

¿Cuáles son las consecuencias de esta alucinación de libertad tras el asesinato de la madre? Kristeva explora la vertiente lingüística y sexual de este proceso en las siguientes páginas de Étrangers à nous-mêmes: "S'arracher à sa famille, à sa langue, à son pays pour venir se poser ailleurs, est une audace qu'accompagne une frénésie sexuelle : plus d'interdit, tout est possible" (47). Resulta llamativo cómo en este caso familia, lengua y país forman una especie de frente monolítico que constituye la fuente de todas las inhibiciones del individuo, unidad que parece confirmarse en las reflexiones posteriores de Kristeva en torno al matricidio lingüístico. La liberación materno-lingüística se traduce acto seguido en un ansia de experimentación erótica, lingüística y conceptual: "Quelle insolite libération du langage ! Privé des brides de la langue maternelle, l'étranger qui apprend une nouvelle langue est capable en elle des audaces les plus imprévisibles : aussi d'ordre intellectuel qu'obscène" (48-49).

Tal y como señala Klosty Beaujour, la escritura en una segunda lengua se ha asociado a menudo con una sensación bien de liberación o de culpabilidad sexual, principalmente usando los ejemplos de Elsa Triolet y Vladimir Nabokov (41). Steiner consideraba que el incesto era el tropo central mediante el que Nabokov expresaba su práctica multilingüe $(1972,19)$, mientras que Elsa Triolet expresó su sensación de culpabilidad al escribir en dos idiomas (ruso y francés) utilizando la metáfora de una bigamia traumática (54 y 84). Los ejemplos podrían multiplicarse: Adorno compara las palabras de origen extranjero con atractivas muchachas exóticas (218), mientras que, en un artículo aparecido en el diario quebequés La Presse, Nathalie Petrowski acusó a Nancy Huston de renegar de su inglés natal para "casarse" con el francés de París.

En el mismo sentido que Triolet, Kristeva parece indicar que esta liberación no está exenta de peligros: para la autora de origen búlgaro, una experiencia traumática que pone fin a la experimentación puede llegar a "somatizarse" en el extranjero en forma de enfermedad. Kristeva expone el caso de 
una pudorosa estudiante extranjera que, tras su llegada al París del 68, participó con entusiasmo en todo tipo de experimentos sexuales en grupo. Meses más tarde, Kristeva se reencontró en un hospital con la misma estudiante, que había enfermado gravemente tras ser abandonada por su pareja (48). ¿Se trata acaso del precio a pagar por la transgresión de las leyes naturales de la autoridad y la lengua maternas?

A pesar del supuesto "matricidio" y de su marchitamiento constante, la lengua materna no abandona nunca a Kristeva: "Ce langage qui se fane sans jamais vous quitter" $(1988,27)$. En la entrevista televisiva con Bernard Pivot anteriormente citada, Kristeva explica que pese a haber abandonado su lengua, ella nunca la abandonó. "Bulgarie, ma souffrance" comienza explicando cómo el búlgaro regresa en sus sueños, cómo puede nadar libremente en él tras pocas horas de inmersión y cómo su lengua materna se ofrece como un salvavidas a la hora de utilizar otros códigos como el inglés o las matemáticas (42). Pierre-Louis Fort identifica el sugestivo uso de imágenes acuáticas (el nado, el salvavidas, la inmersión) que remiten al cuerpo de la madre e incluso a la homofonía entre "mère", madre y "mer", mar (5). En resumen, la lengua materna es para Kristeva un importante foco afectivo construido a partir de imágenes que remiten al cuerpo de la madre, ya sea en la vertiente acogedora del seno materno primigenio o en la figura del matricidio arquetípico como paso doloroso pero necesario para una liberación o autoafirmación personal que puede, en algunos casos, acabar derivando en una enfermedad.

Frente a la concepción orgánica y afectiva de la lengua materna en Étrangers à nous-mêmes, la segunda lengua se presenta acompañada de matices de artificialidad y de operatividad: "Pourquoi alors avoir coupé la source maternelle des mots? Qu'imaginiez-vous de ces nouveaux interlocuteurs auxquels vous vous adressez avec une langue artificielle, une prothèse ?" (28). ¿Es posible llegar a dominar esta prótesis (nótese la semejanza con la metáfora empleada por Nabokov de aprender a usar la mano tras perder varios dedos) hasta el punto de poder crear literatura con ella o, mejor dicho, en ella? La respuesta, como suele ser habitual en Kristeva, es compleja. La mayoría de extranjeros pueden intentar perfeccionar el uso de esta nueva herramienta con el deseo de llegar a poder asimilarse al nuevo idioma algún día: "Vous vous perfectionnez dans un autre instrument, comme on s'exprime avec l'algèbre ou le violon. Vous pouvez devenir virtuose avec ce nouvel artifice" (27). Sin embargo, la nueva lengua seguirá siendo artificial, un mero instrumento disociado del cuerpo sin ninguna capacidad afectiva ni creadora: 
Comme dans une hallucination, ses constructions verbales -savantes ou scabreuses- roulent sur le vide, dissociées de son corps et de ses passions, laissées en otages à la langue maternelle. En ce sens, l'étranger ne sait pas ce qu'il dit. Son inconscient n'habite pas sa pensée, aussi se contente-t-il de faire une re-production brillante de tout ce qu'il y a à apprendre, rarement une innovation. (49, cursiva en el original)

Kristeva admite la posibilidad de innovación en la lengua extranjera, pero la reserva únicamente para los "genios" y "artistas" que se someten a un psicoanálisis o llevan a cabo lo que la autora búlgara define como "un viaje interior en la memoria y el cuerpo" que permita la fusión entre lo propio y lo ajeno (49-50). Estas reflexiones parecen elevar al escritor bilingüe a la más extraordinaria excepcionalidad, una idea profundamente arraigada en la conciencia colectiva de la época de las literaturas nacionales que los estudios dedicados al multilingüismo literario se han esforzado en erradicar insistiendo en la abundancia de ejemplos de escritores que han producido -e innovado- en una segunda lengua. ${ }^{4}$ Resulta indudablemente llamativo que Kristeva desarrolle las ideas sobre la excepcionalidad del escritor bilingüe precisamente desde una segunda lengua. ¿Hemos de entender que se considera a sí misma como uno de estos pocos genios creadores que consiguen ser originales en una segunda lengua? ¿O quizás se trate más bien de una manera velada de confesar la propia incapacidad, de estar condenada a repetir eternamente todo lo que hay que aprender en la segunda lengua, a una suerte de "silencio de los políglotas" al que alude ella misma?

Julia Kristeva acabaría convirtiéndose ella misma en novelista en lengua francesa poco después de la publicación de Étrangers à nous-mêmes. Entrevistada por Ivantcheva-Merjanska y Vialet, Kristeva señala que, tras el doloroso proceso de paso del búlgaro al francés en sus primeros escritos teóricos, descrito en términos de muerte y resurrección, vuelve a experimentar un sentimiento de renacer cada vez que escribe novelas. Sin embargo, el proceso de

4. Para una recopilación de poetas bilingües hasta el siglo Xx, ver Foster. Para un listado no exhaustivo de escritores bilingües contemporáneos (sobre todo en inglés), ver Lvovich/Kellman. Para una recopilación de escritores extranjeros en lengua francesa, ver Brincourt. Para una base de datos de escritores multilingües migrantes en lenguas ibéricas, ver Domínguez/Justo. Carmine Chiellino, él mismo escritor en lengua alemana de origen italiano, dirigió un estudio que da cuenta de los numerosos casos de escritores migrantes en lengua alemana. Incluso una lengua no muy extendida por el mundo como el italiano cuenta con más de 500 escritores vivos procedentes de otros ámbitos lingüísticos según la base de datos BASILE $\mathcal{L} L I M M$ dirigida por Armando Gnisci. 
escritura literaria ya no es una transformación dolorosa, sino más bien un momento de gozo (169). La idea de muerte y resurrección, en consonancia con los intereses cristológicos que Kristeva ha explorado en numerosas obras, aparece ya en Étrangers à nous-mêmes aplicada a la adquisición de la segunda lengua. La resurrección se lleva a cabo en un nuevo cuerpo que es incluso del sexo contrario: "Vous avez le sentiment que la nouvelle langue est votre résurrection : nouvelle peau, nouveau sexe" (27). La misma imagen resurge en la Stéphanie de Possessions: "En glissant à une autre langue, je pratique une forme de transsexualisme" (34); "il lui semblait que jusqu’à ses seins, son dos, son ventre, ses cuisses, ses mains changeaient eux aussi lorsqu'elle passait du français au santabarbarois" (235-36). En este caso, la liberación y la transgresión sexual se conjugan con una nueva identidad lingüística.

Tras comparar las trayectorias de varios escritores de origen ruso que pasaron a escribir en francés o en inglés, Elizabeth Klosty Beaujour propone la existencia de un patrón común en el recorrido lingüístico de los escritores bilingües. Este proceso comienza con una fase traumática de obsesión por mantener la pureza lingüística en la lengua materna y por alcanzarla en la segunda lengua ("asimilarse" en el sentido kristeviano). Si superan este primer periodo traumático, los escritores bilingües pueden llegar a alcanzar hacia el final de su carrera una suerte de liberación creativa al aceptar el hecho de que en la base de sus vidas y de su literatura yace una "matriz polilingüística" (27). ${ }^{5}$ Esta misma trayectoria podría aplicarse al viaje lingüístico de Kristeva. Como hemos visto, la pérdida de lengua materna se describe en términos funestos de enfermedad y muerte, mientras que el proceso de adquisición del segundo idioma, pese a que Kristeva ya lo dominaba hasta cierto punto antes de llegar a Francia, se presenta como un combate: "Au début, ce fut une guerre froide avec ceux du nouvel idiome, désiré et rejetant : puis la nouvelle langue vous a recouvert comme une marée lente, de mortes eaux" (1988, 28-29). Solo más tarde, tras el episodio del psicoanálisis y el nacimiento de su hijo, pero sobre todo con el comienzo de su gozosa actividad literaria, Kristeva acaba por aceptar su identidad a caballo entre el búlgaro y el francés. En 1998, ya con tres novelas en su haber, Kristeva habla de una identidad lingüística mixta utilizando las siguientes palabras:

5. La "matriz polilingüística" es un término que Klosty Beaujour toma prestado de Steiner para aplicarlo al conjunto de escritores rusos que forman su corpus. En Extraterritorial, Steiner se refería a la matriz polilingüística como el factor determinante en toda la vida y obra de Nabokov $(1972,18)$. 
J'ai beau ressusciter en français, depuis presque cinquante ans déjà, mon goût français ne résiste pas toujours aux soubresauts d'une ancienne musique lovée autour d'une mémoire encore vigile. De ces vases communicants émerge une parole étrange, étrangère à elle-même, ni d'ici, ni de là, une monstrueuse intimité. Comme ces caractères du "Temps retrouvé" où Proust voit s'incarner en espaces démesurés les longues années de leurs mémoires volontaires et involontaires, je suis un monstre de carrefour. (1995, 43; cursiva mía)

Kristeva sigue considerando su lengua "híbrida", combinación del gusto francés con los ecos de la música de la lengua materna, como una intimidad "monstruosa", es decir, como un espacio lleno de connotaciones de enfermedad y de aberración corporal. Sin embargo, al mismo tiempo anuncia su resignación a su destino entre dos lenguas y, de paso, trata de erigirse no solo como una criatura aberrante sino también como un monstruo en el sentido de artista genial capaz de crear en un idioma distinto de la lengua materna.

¿De dónde procede esta concepción monstruosa del escritor entre dos lenguas? ¿Cuál es el origen de las incesantes imágenes de disrupción del cuerpo "normal" y maternal -cuerpo enfermo, discapacitado, cadaverizado, en el caso del búlgaro; cuerpo artificial, de otro sexo en el caso del francés- que despliega sistemáticamente Kristeva al hablar del bilingüismo? Por una parte, el papel clave del cuerpo y de la maternidad no se limita a los textos referentes al bilingüismo, sino que se extiende por cada rincón de la obra de la autora de origen búlgaro. A la filiación freudiana y lacaniana de estos elementos se une, en opinión de Ivantcheva-Merjanska (130 y 158), la fenomenología de MerleauPonty. Lengua y corporalidad aparecen en efecto íntimamente relacionados en las ideas del pensador francés: la lengua no sería en ningún caso el envoltorio del pensamiento, sino su inseparable "cuerpo" -término clave en toda la teoría de Merleau-Ponty- u "organismo" en el mundo sensible. Por tanto, las palabras e incluso el tono poseen ya una primera capa de significación en forma de carga afectiva (Merleau-Ponty 211-12). Sin negar la influencia de MerleauPonty sobre el pensamiento lingüístico de Kristeva, hemos de recordar que este tipo de imágenes corporales y afectivas se repiten con desconcertante regularidad en numerosos escritores bilingües del siglo XX. ¿Comparten acaso Vladimir Nabokov, Agota Kristof y Nancy Huston, por citar solo algunos ejemplos, una fascinación secreta por la fenomenología merleaupontiana?

Numerosos estudiosos del multilingüismo literario han señalado la influencia ejercida por las teorías románticas en torno a la lengua y la literatura 
nacional en la recepción de las prácticas literarias multilingües. Las ideas de Johann Gottfried Herder, Wilhelm von Humboldt y Friedrich Schleiermacher extendieron la opinión de que únicamente era posible pensar, sentir y expresarse en la lengua materna (Yildiz 7). Herder insistió en el valor único de cada idioma, considerado como la emanación del espíritu de la nación, utilizando para ello un vocabulario orgánico y afectivo que abundaba en términos como "lenguas vírgenes" (Sdun 26). La aplicación de estas ideas al ámbito literario se traduce en la equivalencia del genio de la lengua con respecto al genio de la literatura nacional (Herder 147). Humboldt adoptó una posición relativista extrema al defender que cada idioma determina el tipo de pensamiento. El idioma sería la manifestación exterior del espíritu mental o Geist de cada pueblo: el uno no podría entenderse sin el otro (60-62). Schleiermacher, usando una imagen orgánica de la lengua materna cargada de connotaciones afectivas, acabó concluyendo que resultaba del todo imposible escribir en una lengua extranjera y que los escritores bilingües se asemejaban a "Doppelgänger" o dobles que no respetaban las leyes naturales (63). Estas ideas allanaron el camino a lo que Yildiz denomina el "paradigma monolingüe" (7-9), que se traduciría en un conjunto de filologías nacionales monolingües de las cuales quedaba excluida la literatura escrita en un idioma distinto de la lengua materna. Como consecuencia, este tipo de literatura, relativamente abundante hasta finales del siglo XVIII, se percibió como excepción o aberración hasta fechas muy recientes (Stockhammer/Arndt/Naguschewski 7).

$\mathrm{El}$ incremento de los flujos migratorios a lo largo del siglo $\mathrm{xx}$, en el que a las sucesivas oleadas de refugiados políticos y religiosos se unieron millones de inmigrantes económicos, tuvo como una de sus muchas consecuencias la multiplicación de los textos escritos en una segunda lengua. Es en este contexto donde surge el "paradigma postmonolingüe", un campo de tensión en el que el paradigma monolingüe sigue ejerciendo su influencia pero en el que las prácticas multilingües se vuelven cada vez más habituales (Yildiz 5). Como hemos señalado, numerosos escritores multilingües describen su paso de una lengua a otra en términos que recuerdan poderosamente a los utilizados por los teóricos románticos: excepcionalidad, monstruosidad y desobediencia de las leyes de la naturaleza, transgresión de prohibiciones sexuales, traición a la lengua materna, etc. No se trata de una experiencia universal, ya que otros escritores bilingües han asociado su cambio de lengua a un proceso de liberación política con respecto a los traumas inscritos en la lengua materna o han elegido una nueva lengua que para ellos era símbolo de libertad y tolerancia, como 
fue el caso de la mayoría de exiliados españoles que decidieron adoptar la lengua francesa como lengua literaria (Molina Romero 125).

Kristeva conoce bien la filiación romántico-nacionalista del concepto de lengua nacional e incluso el gusto de Herder por las metáforas corporales y afectivas en su exaltación de la virginidad original de las lenguas $(1988,265)$. No obstante, sea por vía directa gracias el poderoso anclaje del paradigma monolingüe incluso en la época del resurgir de la literatura multilingüe, o por vía indirecta mediante la posible influencia de Humboldt sobre Merleau-Ponty a través de Cassirer (Springstübe 60), Kristeva reproduce este mismo tipo de discurso al hablar de la lengua materna como cuerpo enfermo y cadaverizado, de la segunda lengua como prótesis o cuerpo artificial y de sí misma como monstruo.

Para Kristeva, una de las principales características de su intimidad "monstruosa" formada por el cruce de lenguas es que, como el título del libro de 1988, es extranjera o extraña para sí misma. Utilizando el inconsciente freudiano, Kristeva culmina Étrangers à nous-mêmes negando la unicidad del sujeto y ubicando la alteridad no en una nación ni en una raza, sino en el interior de cada ser humano: "Nous sommes nos propres étrangers -nous sommes divisés-" (268). El psicoanálisis sería entonces la herramienta que nos permitiría realizar un viaje hacia lo extraño de los otros y de nosotros mismos, encaminándonos hacia una ética del respeto por lo irreductiblemente extraño (269). En efecto, todo el proyecto del libro se resume en un intento de acercamiento al extranjero (o a "lo extranjero") respetando su propia diferencia y no en una estrategia de asimilación o fijación que acabaría por anularla. Esta estrategia pasa necesariamente por la constatación del carácter fragmentario del sujeto, por el reconocimiento de sus contradicciones y por la aceptación de lo irreduciblemente extranjero en nosotros mismos. En este sentido, se podría calificar a la obra de Kristeva como una hermenéutica de lo extranjero y de lo propio.

En la confrontación con textos procedentes de otras culturas, la denominada "hermenéutica intercultural" ofrece otra forma de acercamiento a la cultura extranjera y a los prejuicios del lector -en el sentido gadameriano- que constituirían una suerte de extranjero "interior". Partiendo de la hermenéutica de Gadamer y de la estética de la recepción de Jauss e Iser, un grupo de profesores de alemán como lengua extranjera con una amplia experiencia en diversos países asiáticos trataron de elaborar una base teórica para la interpretación de la literatura alemana por alumnos procedentes de culturas tan distantes como la japonesa, la china o la ceilandesa. Para sus principales teóricos, Dietrich Krusche y Alois Wierlacher, resultaba indispensable fundar una "her- 
menéutica intercultural", capaz de dar cuenta de la diversidad de los acercamientos a la cultura alemana y a su literatura, sin que el alejamiento cultural supusiese en ningún caso un hándicap o un obstáculo para la comprensión (Wierlacher, $\mathrm{x}$ ). Al contrario, es precisamente la puesta en común de una diversidad de perspectivas y no solo la limitación a la perspectiva de la propia tradición la que daría lugar a una mejor comprensión de la literatura. Asimismo -y es aquí donde el paralelo con las teorías de Kristeva es más evidente- la confrontación con un texto extranjero y posiblemente con una serie de interpretaciones también extranjeras exige la toma de conciencia de lo irreductiblemente extranjero o extraño de la propia posición.

La hermenéutica había sufrido hasta ese momento una grave limitación al prestar atención únicamente a la dimensión histórica. En efecto, la fusión de horizontes gadameriana se entendía como una operación llevada a cabo dentro del contínuum de la misma tradición: tanto el texto como el lector pertenecían a la misma cultura, la occidental. Para Krusche y Wierlacher, el proceso interpretativo que requiere la confrontación de un lector oriental con un texto occidental (o viceversa) ${ }^{6}$ necesita, además de la dimensión histórica, de una dimensión "espaciocultural” (Krusche 8). En todo caso, la hermenéutica intercultural rechaza de plano la fusión de horizontes en tanto que esta persigue la "unidad" de perspectivas (Gadamer 1972, 11), lo cual implicaría necesariamente una disolución de "lo ajeno" o "lo extranjero" -das Fremde en alemán-, tal y como el propio Gadamer sostiene (Gadamer 1976, 104). Frente a este procedimiento, que Wierlacher tacha de colonialista, la hermenéutica intercultural trata de mantener en todo momento las distancias y reconocer la alteridad cultural del texto sin pretender ni apropiársela ni disolverla en una supuesta fusión con lo propio (11).

El lector de un texto alejado en el tiempo pero perteneciente a su misma tradición dispone de una serie de conocimientos y orientaciones previas que guían y acotan su interpretación. Al formar parte de un mismo contínuum cultural que va desde la época en la que apareció el texto al presente, el lector presupone una cierta identificación con la obra, por lo que trata, guiado por su bagaje interpretativo, de centrarse en lo irreductiblemente extraño o ajeno del texto, manteniendo en todo momento las distancias con él. En el caso de un

6. Además de a su actividad como profesor de lengua y literatura alemana en Sri Lanka y Japón, Krusche desarrolló gran parte de sus teorías a partir de las reflexiones en torno a la recepción del género haiku en Alemania (Krusche 104-17). 
texto procedente de otra cultura se produce el fenómeno inverso. El lector presupone de partida una extrañeza total y tiende a focalizar su atención en los aspectos con los que puede identificarse (centrándose únicamente en lo que Krusche elocuentemente llama "reacciones 'ajáa"), con lo cual elimina o sencillamente ignora la alteridad irreductible de la obra extranjera (Krusche 130).

Este tipo de lectura no asimiladora de textos procedentes de otra tradición se caracteriza sobre todo por ser una lectura ralentizada -sobre todo si el texto está escrito en una lengua extranjera-, lo cual implica una interpretación más atenta e intensa en la que el lector, en el encuentro con una cultura desconocida, desautomatiza sus propios conceptos, costumbres y modelos de comportamiento, tal y como sucede en un viaje a un país extranjero (Wierlacher 17). La alteridad cultural no se percibe por tanto en este caso como un obstáculo que impide la interpretación, sino como la condición para que el lector sea consciente de su propia especificidad al delimitarse a sí mismo frente a la otredad del texto (Krusche 129).

$\mathrm{El}$ aula de literatura en lengua alemana para extranjeros forma el original circuito de pruebas de la hermenéutica intercultural. Uno de los ejemplos utilizados por Krusche para ilustrar sus teorías es la recepción de un poema de Goethe, "Auf dem See" ("En el lago") por parte de un grupo de sus estudiantes de alemán de Sri Lanka. El poema, que como es típico de la lírica no solo de Goethe sino también de gran parte de la tradición occidental, es un canto a las bondades de la madre naturaleza, suscitó una controvertida reacción entre los estudiantes ceilandeses. En efecto, para este grupo de estudiantes, que al igual que la mayoría de la población de Sri Lanka profesaba una de las ramas más estrictas del budismo, la naturaleza no es como para Goethe la fuente del bien y la belleza, sino una ilusión engañosa, una mera apariencia tentadora que puede desviar al hombre del camino hacia la iluminación. La primera reacción de los estudiantes frente al texto fue formular su propia concepción de la naturaleza, para acto seguido interesarse por las a su juicio extrañas e inverosímiles ideas goetheanas y tratar de interpretar el poema a la luz de estos nuevos datos. Es decir, el contacto con el texto extranjero provocó en primer lugar la movilización y delimitación de los conceptos e ideas que forman los prejuicios o la visión del mundo de la cultura propia. Una vez delimitada esta diferencia, los estudiantes trataron de acercarse al mundo del texto sin tratar en ningún momento de identificarse con él o de cancelar su alteridad fundamental. Por supuesto, este tipo de reacciones son de interés no solo para el estudiante sino para el profesor que descubre que las ideas supuestamente uni- 
versales de la propia cultura, tales como la fascinación por la belleza natural, pueden ser interpretadas como una alteridad radical y forman en realidad parte de sus propios prejuicios (Krusche 133-34).

Podría decirse que el movimiento pendular de la hermenéutica intercultural, que exige en un primer momento una salida hacia el contacto con el otro para volver a continuación hacia el interior con el objetivo de encontrar lo genuinamente propio, no es sino una reformulación de la dinámica propia de la Bildung tal y como esta se presenta desde Schelling y Goethe (autocomprensión del espíritu a través de su salida y su posterior retorno a sí mismo), pero sobre todo en la vertiente de Friedrich Schlegel, Novalis y Goethe, que hacen hincapié tanto en la función mediadora del contacto con el extranjero en forma de viaje o peregrinación, como en la necesidad de delimitación de lo propio y lo ajeno sin caer en la asimilación. ' Siguiendo esta tradición, la hermenéutica intercultural se caracteriza por su apertura hacia el extranjero y el reconocimiento del papel que el contacto con textos procedentes de otras culturas desempeña en el autoconocimiento del lector.

En este sentido, podría decirse que Étrangers à nous-mêmes y la hermenéutica intercultural poseen una orientación ética similar: el respeto de las diferencias culturales para una mejor comprensión de la propia cultura y de la cultura extranjera en el caso de la hermenéutica intercultural (Wierlacher, $\mathrm{x}$ ) y el acercamiento no-asimilacionista al extranjero a partir de la constatación que todos somos ya extranjeros para nosotros mismos en el caso de Kristeva. Sin embargo, estas dos aproximaciones hermenéuticas a lo propio y lo ajeno difieren principalmente en dos puntos. En primer lugar, mientras que para Kristeva el verdadero acercamiento al extranjero solo se produce después de la toma de conciencia del carácter fragmentario y contradictorio de la propia identidad, para la hermenéutica intercultural es el contacto con el extranjero, en este caso en forma de texto literario extranjero, el que permite definir la propia identidad: el reconocimiento de la alteridad en primer lugar es la condición de la delimitación de la propia identidad (Wierlacher, XI). La segunda diferencia reside en la base conceptual de cada aproximación: mientras que para Kristeva, que parte evidentemente de la tradición psicoanalítica, el extranjero es ante todo un sujeto dividido, para la hermenéutica intercultural el extranjero se entiende a menudo como una cultura nacional unitaria. Precisamente este punto de la hermenéutica intercultural es el que ha suscitado más

7. Para un acercamiento al concepto de Bildung, ver Berman 72-86. 
críticas. Pese a la constatación por parte de sus teóricos de que, además de la cultura, también la clase social o el nivel de educación determinan la historicidad de la posición del lector (Krusche 143), la preferencia por la determinación cultural ha sido cuestionada como una colectivización o nacionalización de la interpretación. Es decir, el lector deja de ser un individuo para ser una colectividad que casi siempre coincide con la nación (Leskovec 92).

A pesar de sus limitaciones, la hermenéutica intercultural se presenta como una poderosa herramienta no solo en el aula de literatura para extranjeros. Una interpretación no asimiladora de los textos procedentes de otra cultura puede, en virtud de sus condiciones especiales, incluso considerarse como un ejemplo hermenéutico extremo que pone de relieve las condiciones generales de interpretación de todo tipo de textos literarios (Krusche 130). Este tipo de lecturas desde lo irreductiblemente otro a lo extrañamente propio, así como los viajes de Kristeva al interior del sujeto dividido como requisito para el conocimiento del otro, son hoy en día más necesarios que nunca. Tras el fracaso de los proyectos de asimilación cultural, solo un conocimiento propio y del otro que sea capaz de reconocer y apreciar lo irreductiblemente extraño de cada uno podrá tener posibilidades de éxito tanto en nuestras sociedades multilingües, multiculturales y transculturales como en unos estudios literarios que van más allá de las fronteras lingüísticas y nacionales. Y es precisamente en los ejemplos de las contradicciones de la lengua materna y la segunda lengua expuestos por Kristeva así como del ejemplo extremo de la enseñanza de literatura a extranjeros que nos ofrece la hermenéutica intercultural donde mejor podemos oír nuestra propia voz como palabras extrañas a sí mismas y reconocernos como extranjeros para nosotros mismos.

\section{OBRAS CITADAS}

Adorno, Theodor W. "Wörter aus der Fremde". Noten zur Literatur. Vol. 2. Frankfurt a.M.: Suhrkamp, 1959. 216-232.

Barthes, Roland. "L'Étrangère". Euvres complètes. Vol. 3. Paris: Seuil, 2002. 477. Bennani, Jalil. Du Bilinguisme. Paris: Denoel, 1985.

Berman, Antoine. L'Épreuve de l'étranger: Culture et traduction dans l'Allemagne romantique. Paris: Gallimard, 1984.

Brincourt, André. Langue française terre d'accueil. Mónaco: Éditions du Rocher, 1997.

Calero, Ana R., Domingo Pujante y Miguel Teruel. "De fronteras y exilios". Quaderns de Filologia. Estudis literaris 12 (2007): 9-25. 
Chiellino, Carmine, ed. Interkulturelle Literatur in Deutschland: Ein Handbuch. Stuttgart/Weimar: Metzler, 2000.

Domínguez, César, y Susana Justo. Migra: Database of Migrant Writers in Iberian Languages. 5 de mayo de 2017. <http://www.migrantwriters.org>.

Fort, Pierre-Louis. "At the Crossroads of Language and Identity: Julia Kristeva's Bilingualism”. Power, Memory, and Culture: Cultural Constructions Symposium Proceedings and Other Presentations (2007): 1-10. 5 de mayo de 2017. < http://www.uta.edu/modl/pdf/culcon/200705/fort.pdf>.

Foster, Leonard. The Poet's Tongues: Multilingualism in Literature. London: Cambridge UP, 1970.

Gadamer, Hans-Georg. Wahrheit und Methode: Grundzüge einer philosophischen Hermeneutik. Tubinga: Mohr, 1972.

Gadamer, Hans-Georg. Kleine Schriften. Tubinga: Mohr, 1976.

Gaus, Günter. "Hannah Arendt". Zur Person. Rundfunk Berlin-Brandenburg, 26 de octubre de 1964.

Gnisci, Armando. Banca dati degli Scrittori Immigrati in Lingua Italiana e della Letteratura Italiana della Migrazione Mondiale (BASILI\&LLIMM). (19972017). 15 de mayo de 2017. <http://basili-limm.el-ghibli.it/>.

Guillén, Claudio. El sol de los desterrados: literatura y exilio. Barcelona: Quaderns Crema, 1995.

Herder, Johann Gottfried. "Ueber die neuere Deutsche Literatur”. Sämmtliche Werke. Ed. Bernhard Suphan. Vols. 1 y 2. Berlin: Weidmann, 1877. Hoffman, Eva. Lost in Translation. London: Heinemann, 1989.

Humboldt, Wilhelm von. Über die Verschiedenheit des menschlichen Sprachbaues und ibren Einfluß auf die geistige Entwicklung des Menschengeschlechts. Ed. Herbert Nette. Darmstadt: Claassen \& Roether, 1949.

Huston, Nancy, y Laila Sebar. Lettres parisiennes. Paris: Barrault, 1986.

Ivantcheva-Merjanska, Irene. "Assia Djebar et Julia Kristeva: choisir le français comme langue d'écriture". Tesis doctoral. University of Cincinnati, 2011. 5 de mayo de 2017. <https://etd.ohiolink.edu/!etd.send_file?accession $=u$ cin $1307104630 \&$ disposition $=$ inline $>$.

Ivantcheva-Merjanska, Irene, y Michèle Vialet. "Entretien avec Julia Kristeva: Penser en nomade et dans l'autre langue le monde, la vie psychique et la littérature". Cincinnati Romance Review 35 (2013): 158-89.

Kellman, Steven G. The Translingual Imagination. Lincoln/Londres: University of Nebraska Press, 2000. 
Klosty Beaujour, Elizabeth. Alien Tongues: Bilingual Russian Writers of the 'First' Emigration. Ithaca: Cornell UP, 1989.

Kremnitz, Georg. Mehrsprachigkeit in der Literatur. Wien: Praesens, 2015.

Kristeva, Julia. Semeiotikê: Recherches pour une sémanalyse. Paris: Seuil, 1969.

Kristeva, Julia. "Mémoire". L'Infini 1 (invierno 1983): 39-54.

Kristeva, Julia. Étrangers à nous-mêmes. Paris: Fayard, 1988.

Kristeva, Julia. Soleil noir: Dépression et mélancolie. Paris: Gallimard, 1989.

Kristeva, Julia. Le Vieil Homme et les loups. Paris: Fayard, 1991.

Kristeva, Julia. "Bulgarie, ma souffrance". L'Infini 51 (otoño 1995): 42-52.

Kristeva, Julia. Possessions. Paris: Fayard, 1996.

Kristeva, Julia. L'Avenir d'une révolte. Paris: Calmann-Lévy, 1998.

Kristeva, Julia. Mélanie Klein: Le génie féminin. Paris: Fayard, 2000.

Kristeva, Julia. Au Risque de la pensée. La Tour d'Aigues: L’Aube, 2001.

Kristeva, Julia. Meurtre à Byzance. Paris: Fayard, 2004.

Kristof, Agota. "Langue maternelle et langues ennemies". L'Analphabète: Récit autobiographique. Genève: Zoé, 2004. 21-24.

Krusche, Dietrich. Literatur und Fremde: zur Hermeneutik kulturräumlicher Distanz. München: Iudicium, 1985.

Leskovec, Andrea. Einfuibrung in die interkulturelle Literaturwissenschaft. Darmstadt: Wissenschaftliche Buchgesellschaft, 2011.

Lvovich, Natasha, y Steven G. Kellman. "Introduction to Special Issue: Literary Translingualism: Multilingual Identity and Creativity". L2 Journal 7.1 (2015): 3-5.

Merleau-Ponty, Maurice. Phénoménologie de la perception. Paris: Gallimard, 1976.

Molina Romero, M. Carmen. "Écrivains espagnols d'expression française: une littérature exilée dans la langue de l'autre". Quaderns de Filologia. Estudis literaris 12 (2007): 117-30.

Nabokov, Vladimir. Strong Opinions. Londres: Penguin, 2011.

Petrowski, Nathalie. "Bar payant". La Presse: Cahier Sortir [Montréal] 18 noviembre 1993: D3.

Pivot, Bernard. Double je. France Télévisions. 26 de junio de 2003.

Schleiermacher, Friedrich. "Ueber die verschiedenen Methoden des Uebersetzens". Das Problem des Übersetzens. Ed. Hans Joachim Störig. Darmstadt: Wissenschaftliche Buchgesellschaft, 1963.

Sdun, Winfried. Probleme und Theorien des Übersetzens in Deutschland vom 18. bis 20. Fabrbundert. München: Max Huber, 1967. 
Springstübe, Darja. Über Wabrnebmung und Ausdruck in der Philosophie Maurice Merleau-Pontys. Berlin: Logos, 2013.

Steiner, George. Extraterritorial: Papers on Literature and the Language Revolution. London: Faber and Faber, 1972.

Steiner, George. After Babel: Aspects of Language and Translation. Oxford: Oxford UP, 1975.

Stockhammer, Robert, Susan Arndt y Dirk Naguschewski. "Einleitung: Die Unselbstverständlichkeit der Sprache”. Exophonie: Ander-Sprachigkeit (in) der Literatur. Eds. Susan Arndt, Dirk Naguschewski y Robert Stockhammer. Berlin: Kadmos, 2007. 7-27.

Todorov, Tzvetan. Nous et les autres: la réflexion française sur la diversité bumaine. Paris: Seuil, 1989.

Triolet, Elsa. La Mise en mots. Genève: Skira, 1969.

Wierlacher, Alois. Das Fremde und das Eigene: Prolegomena zu einer interkulturellen Germanistik. München: Iudicium, 2000.

Yildiz, Yasemin. Beyond the Mother Tongue: The Postmonolingual Condition. New York: Fordham UP, 2012. 